Journal of Physical Science, Vol. 32(3), 31-44, 2021

\title{
Conductive Polymer Composites Made from Polypropylene and Recycled Graphite Scrap
}

\author{
Dylan Jia Yee Tong, ${ }^{1}$ Seong Chun Koay, ${ }^{1 *}$ Ming Yeng Chan, ${ }^{2}$ Kim Yeow Tshai, ${ }^{3}$ Thai \\ Kiat Ong, ${ }^{2}$ and Yose Fachmi Buys ${ }^{4}$
${ }^{1}$ School of Computer Science and Engineering, Faculty of Innovation and Technology,
Taylor's University Lakeside Campus, No. 1, Jalan Taylor's, 47500 Subang Jaya, Selangor, Malaysia
${ }^{2}$ Faculty of Engineering and Technology, Tunku Abdul Rahman University College, Jalan Genting Kelang, Setapak, 53300 Kuala Lumpur, Malaysia
${ }^{3}$ Faculty of Engineering, The University of Nottingham, Jalan Broga, 43500 Semenyih, Selangor, Malaysia
${ }^{4}$ Department of Mechanical Engineering, Faculty of Engineering, University of Malaya, 50603 Kuala Lumpur, Malaysia

${ }^{*}$ Corresponding author: seongchun.koay@taylors.edu.my

Published online: 25 November 2021

To cite this article: Tong, D. J. Y. et al. (2021). Conductive polymer composites made from polypropylene and recycled graphite scrap. J. Phys. Sci., 32(3), 31-44. https://doi.org/10.21315/jps2021.32.3.3

To link to this article: https://doi.org/10.21315/jps2021.32.3.3

\begin{abstract}
Electric Discharge Machining (EDM) process uses electrodes made from graphite that wear out over time and are turned into scrap. In this research, EDM electrode scraps were recycled and turned into graphite powder (rGP). This rGP was used as a conductive filler to produce conductive polymer composite (CPC) material by combining it with polypropylene (PP) resin via melt compounding and compression moulding processes. The percolation threshold of this composite material changed when $30 \mathrm{wt} \%$ of $r G P$ was added, whereby the insulative material changed became antistatic. The composite was able to achieve surface resistivity as low as $10^{5} \mathrm{ohm} / \mathrm{sq}$. However, the addition of higher rGP content deteriorated the tensile properties of composite, whereby the tensile strength of composite significantly decreased as compared to neat PP. The results also showed that the tensile modulus of this composite became higher, and the material became more brittle as compared to neat PP. However, the PP/rGP composite with $50 \mathrm{wt} \%$ filler content reduced the tensile modulus due to plasticising effect caused by the agglomeration of $r G P$. The addition of high filler content on PP/rGP composite also caused an increase in processing torque. This was due to the restriction of rGP particles to the melt flow of molten PP. The morphological analysis found that the PP/rGP composites with higher amounts of filler content were highly agglomerated and formed conductivity
\end{abstract}

(C) Penerbit Universiti Sains Malaysia, 2021. This work is licensed under the terms of the Creative Commons Attribution (CC BY) (http://creativecommons.org/licenses/by/4.0/). 
paths within the PP matrix. The increase of rGP content highly improved the thermal stability of composite. The findings of this study show that the rGP has the potential to be used as a conductive filler for producing conductive composite material.

Keywords: recycled graphite, polypropylene, conductive polymer composite

\section{INTRODUCTION}

Polymers are good electrical insulators, but they can be tailor-made into conductive materials by combining a polymer with conductive filler. This material is called conductive polymer composites (CPC) as it contains conductive fillers dispersed in polymer matrix. The conductive characteristic of CPC is due to the presence of conductive fillers, and this results in $\mathrm{CPC}$ having a broad range of conductivity which can be controlled by the filler content and type of conductive filler. ${ }^{1}$ There is a wide range of applications of CPC such as semiconducting material for dissipation of static electricity, electromagnetic interference shielding, electronic equipment, and floor heating elements. ${ }^{1,2}$ In the past, CPC materials were mainly produced by adding carbon-based conductive filler, such as carbon black, carbon nanotube, and graphite. ${ }^{3,4}$ However, studies related to the production of CPC material using recycled waste material are relatively rare. Therefore, this research focuses on utilising recycled graphite for producing CPC material.

Graphite is a type of crystalline carbon that is obtained from nature and synthetically prepared from inorganic material. Graphite is a good electrically and thermally conductive material. ${ }^{5}$ For EDM machines, the majority of industries use graphite electrode material. The graphite electrode of EDM machine wear out after certain cycles of usage and requires replacement. Then, the scrap of electrodes is disposed, and it becomes waste. In this context, this research was carried out to recycle graphite electrode scraps that are obtained from EDM machining industry and utilise them as conductive filler in producing CPC.

The present research is focused on the effects of filler content on processing torque, electrical, tensile, thermal, and morphological properties of CPC made from recycled graphite powder (rGP) and polypropylene (PP). Therefore, this research explores the potential of recycling graphite electrode scraps from EDM machines by turning them into conductive fillers to produce conductive composites. 


\section{EXPERIMENTAL}

\subsection{Raw Material}

In this experiment, EDM graphite electrode scraps were collected from Pre-Tech Solution Sdn. Bhd. (Penang, Malaysia). PP-type co-polymer (grade: SM340) was chosen as the matrix to produce CPC. Therefore, the PP resin was purchased from Lotte Chemical Titan (M) Sdn. Bhd. (Johor, Malaysia).

\subsection{Preparation of Conductive Filler}

The collected graphite electrode scrap was recycled by breaking it into small pieces using a hammer. Then, the graphite pieces were ground into fine powder using a miniature powder grinder (Mill Powder Tech, Tainan, Taiwan). The rGP was sieved to obtain particles of homogenous size, which was then ready to be used in the experiment. The size of metal sieve used in this experiment was 200 mesh. The average particle size of obtained rGP was 130 microns as measured by Melvin Particle Analyser (Cambridge, United Kingdom).

\subsection{Preparation of Conductive Composites}

For compounding, rGP was mixed with $\mathrm{PP}$ resin in various filler contents, which were $10 \mathrm{wt} \%, 20 \mathrm{wt} \%, 30 \mathrm{wt} \%, 40 \mathrm{wt} \%, 45 \mathrm{wt} \%$, and $50 \mathrm{wt} \%$, using Brabender ${ }^{\circledR}$ Plastrograph Internal Mixer (Duisburg, Germany). The compounding temperature was fixed at $180^{\circ} \mathrm{C}$ with a rotor speed of $50 \mathrm{rpm}$. For the compounding procedures, PP resin was first transferred into a mixing chamber and was left to melt for $2 \mathrm{~min}$. Then, the rGP was introduced into the melted PP and was allowed to mix for 6 min until the torque stabilised. After that, the rotor was stopped, and the compound was removed from the mixing chamber. During compounding, the data of processing torque against time was recorded by the machine. The PP/ rGP composite compound was further moulded into a sheet of $1 \mathrm{~mm}$ thickness using the Gotech (Taichung, Taiwan) compressing moulding machine (model GT-7014-H30C). The operating temperature was set at $180^{\circ} \mathrm{C}$ and compression pressure at 5 tonnes. For moulding sequence, the compound was first pre-heated in the mould for $6 \mathrm{~min}$, and then, the compound was softened and compressed for $1 \mathrm{~min}$. After $1 \mathrm{~min}$, the mould was left to cool down for $10 \mathrm{~min}$. Lastly, the composite sheet was removed from the mould and further cut into tensile specimens using a dumbbell cutter. The dimensions of tensile specimens were according to ASTM D638, type IV. 


\section{$2.4 \quad$ Testing and Analysis}

The PP/rGP composites with different filler contents were tested for their tensile properties with the aid of Instron (Norwood, United States) universal testing machine (model 5569). The test was carried out by referring to the standard ASTM D638. The crosshead speed of the machine was set to $30 \mathrm{~mm} / \mathrm{min}$ and load cell to $15 \mathrm{kN}$.

PROSTAT ${ }^{\circledR}$ surface resistivity apparatus (Bensenville, United States) was used to measure the surface resistivity of CPCs and the test was done following the standard ASTM D257. The test was conducted using two miniature point probes placed at five different locations on a $100 \mathrm{~mm} \times 100 \mathrm{~mm}$ sheet to obtain surface resistivity. The average values of surface resistivity were recorded.

Thermal properties of the PP/rGP composites were analysed using Pyris Diamond Thermogravimetric Analyser (TGA) (Perkin Elmer, Waltham, United States). The specimen was cut into small sizes with specimen weight of $5 \mathrm{mg}$ to $9 \mathrm{mg}$. Then, the specimen underwent thermal scan from temperatures of $30^{\circ} \mathrm{C}$ to $700^{\circ} \mathrm{C}$ with a heating rate of $10^{\circ} \mathrm{C} / \mathrm{min}$. The analysis was run under nitrogen atmosphere with a nitrogen gas flow rate of $20 \mathrm{ml} / \mathrm{min}$.

Field Emission Scanning Electron Microscope (FESEM) (model FEI Quanta 400, Hillsboro, United States) was used to examine the fracture surface of tensile specimens. Prior to examination, all specimens were coated with an ultrathin layer of gold to prevent electrons from charging during the scanning. The electron acceleration was fixed at $20 \mathrm{kV}$.

\section{RESULTS AND DISCUSSION}

\subsection{Compounding Behaviour}

Figure 1 illustrates the processing torque-time curves of the PP/rGP composites with different filler contents. The results showed a drastic increment of torque in the first min, and then a gradual decrease. This was because the rotor required more torque in the initial stage to shear and melt the solid PP resin, thus, the processing torque increased. When the PP resin had melted due to continuous shearing at high temperature, the torque slowly decreased. When rGP powder was slowly added to the melted PP resin over a period of $2 \mathrm{~min}$, the torque slowly increased. The increase in torque was due to the restriction of rGP particles towards the melt flow. After the compound was homogeneously mixed, the torque became stable, and the mixing process was completed. The first peak lowered as the amount of rGP was 
increased. Then, the second torque peak occurred after $2 \mathrm{~min}$, and it increased as the filler content increased. This phenomenon was caused by the reduction of PP resin that decreased the amount of torque required to shear the PP resin. The change of second peak was correlated with the amount of rGP filler. As the filler content was increased, the restriction from rGP particles also became higher. For this reason, the second observed torque became higher when more rGP was added to the melt. The compounding behaviour of $\mathrm{PP} / \mathrm{rGP}$ composite was like other composites filled with different particle fillers. ${ }^{6,7}$ Table 1 shows that the processing torque of $\mathrm{PP} / \mathrm{rGP}$ compound increased with the increase in filler content. As mentioned earlier, the presence of rGP particles restricted the melt flow of molten PP and increased the viscosity of compound. This finding agreed with the findings reported by Chun et al. They also agreed that the viscosity of composite compound was directly proportional to the increase of filler content. ${ }^{8}$

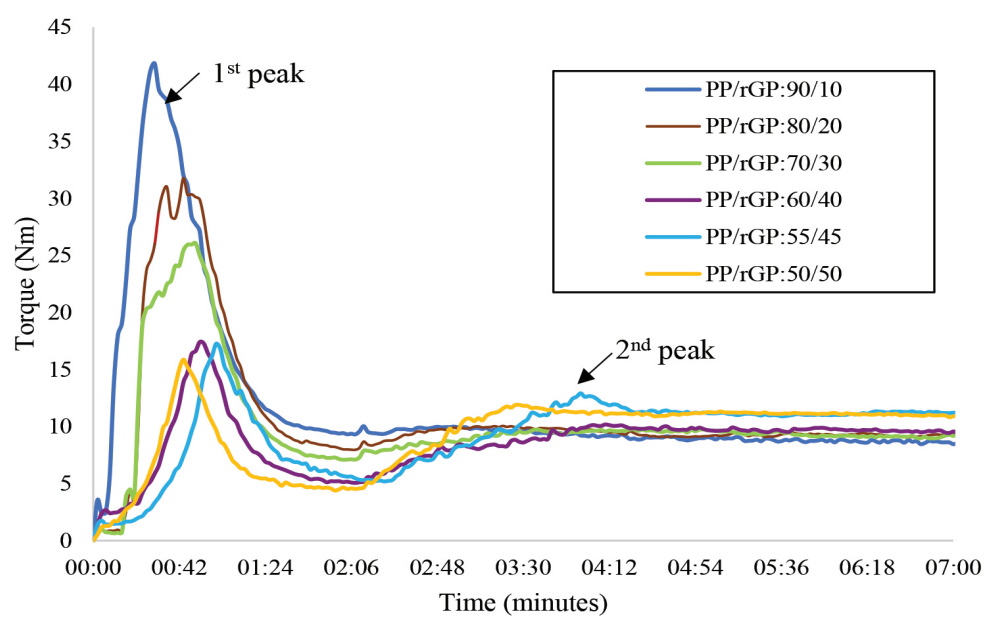

Figure 1: Processing torque verses mixing time of $\mathrm{PP} / \mathrm{rGP}$ with various contents of filler.

Table 1: Stabilised torque of PP/rGP composites with various filler contents.

\begin{tabular}{lc}
\hline Sample & Stabilised torque $(\mathrm{Nm})$ \\
\hline Neat PP & 6.8 \\
PP/rGP:90/10 & 7.2 \\
PP/rGP:80/20 & 8.4 \\
PP/rGP:70/30 & 9.0 \\
PP/rGP:60/40 & 9.5 \\
PP/rGP:55/45 & 9.8 \\
PP/rGP:50/50 & 10.5 \\
\hline
\end{tabular}




\subsection{Electrical Surface Resistivity}

Figure 2 shows the electrical surface resistivity of $\mathrm{PP} / \mathrm{rGP}$ composites with various filler contents. The electrical surface resistivity of $\mathrm{PP} / \mathrm{rGP}$ composites, with filler contents ranging from $10 \mathrm{wt} \%$ to $20 \mathrm{wt} \%$, fluctuated within an insulative range. This occurred because the amount of rGP was insufficient to form a conductive network. However, when the filler content was increased to $30 \mathrm{wt} \%$, the surface resistivity of composite initially decreased, and it significantly reduced from $10^{12} \mathrm{ohm} / \mathrm{sq}$ to $10^{11} \mathrm{ohm} / \mathrm{sq}$ once the filler content reached $30 \mathrm{wt} \%$. This indicated that the conductivity of composite changed from insulative to antistatic. The percolation threshold of PP/rGP composite was found at $30 \mathrm{wt} \%$. When the amount of rGP was above $40 \mathrm{wt} \%$, the surface resistivity of composite dramatically decreased from antistatic to static dissipative region. This indicated that when the filler content exceeded $40 \mathrm{wt} \%$, the rGP particles formed a conductive network within the PP matrix. Therefore, the electrons could move freely around the conductors. The morphological analysis also confirmed that the formation of conductive network occurred in the composite when filler content reached $50 \mathrm{wt} \%$. In the research by Gulrez et al. the conductivity of PP-based conductive composite showed similar percolation trends but the amount of conductive filler to cause percolation threshold was different. ${ }^{9}$ In this study, the amount of filler content that caused percolation threshold was higher because the particle size of the rGP prepared in the experiment was considered large as compared to the sizes used by other researchers. However, the findings proved that the graphite electrode scrap can be recycled and used as a conductive filler.

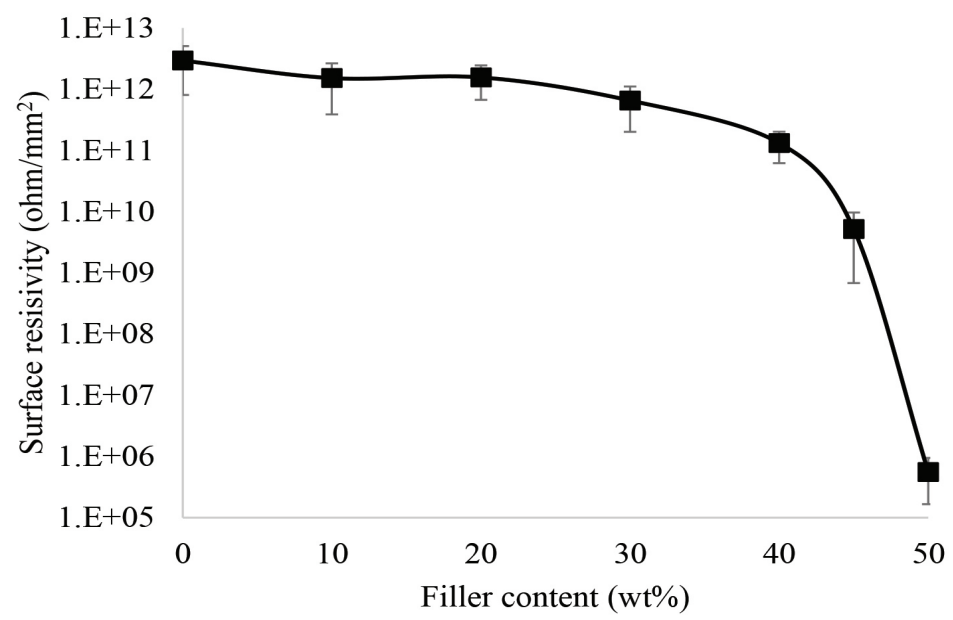

Figure 2: Trendline of electrical surface resistivity over various amounts of filler in PP/ rGP composites. 


\subsection{Tensile Properties}

The tensile strengths of $\mathrm{PP} / \mathrm{rGP}$ composite with different filler contents are displayed in Figure 3. The tensile strength of $\mathrm{PP} / \mathrm{rGP}$ composite decreased when the amount of filler was increased. As compared to neat PP, the tensile strength of composite decreased by approximately $60 \%$ when $50 \mathrm{wt} \%$ of rGP was added. The rGP was particulate and irregular in shape as observed from the scanning electron microscope (SEM) micrograph. Generally, this type of filler has a poor loadbearing capacity. ${ }^{7}$ Furthermore, the rGP was highly agglomerated at high filler content, whereby the agglomeration acted as a stress concentrator. The presence of stress concentrator and a low load-bearing capacity resulted in a lower composite strength. The presence of filler agglomeration was proven by the morphological study as well. The geometrical and stress concentrator factors of the filler were key factors that caused the decrement of strength in the conductive composite filling, as reported by other researchers. ${ }^{10,11}$ In contrast, the tensile modulus of PP/rGP composites increased when the filler content was increased from $10 \mathrm{wt} \%$ to $45 \mathrm{wt} \%$. The addition of rGP particles highly restricted the chain mobility of PP matrix. Therefore, it was concluded that the addition of more rGP content increased the stiffness of composite. However, the tensile modulus of PP/rGP slightly increased when the filler content was increased to $50 \mathrm{wt} \%$, as displayed in Figure 3.

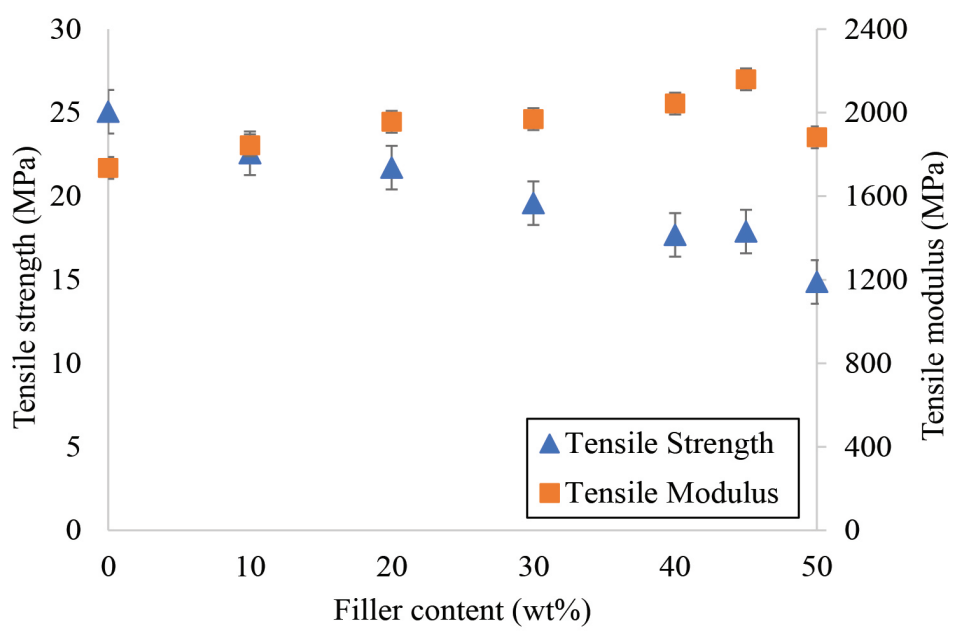

Figure 3: Tensile strength and tensile modulus of $\mathrm{PP} / \mathrm{rGP}$ with various contents of filler.

Figure 3 illustrates that the tensile modulus of PP/rGP composites increased when the filler content increased from $10 \mathrm{wt} \%$ to $45 \mathrm{wt} \%$. When the filler content reached $50 \mathrm{wt} \%$, the tensile modulus of composite decreased. The rGP filler had stiff and rigid particles. It could be concluded that the addition of rGP generally increased 
the stiffness of composites. Furthermore, the addition of rGP restrained the chain mobility of PP matrix due to the friction that occurred at interfacial region. As a result, the composite became more rigid and stiff. According to Bhagat and Verma the addition of more graphite flakes increased the tensile modulus of composites. ${ }^{12}$ However, when the amount of filler reached $50 \mathrm{wt} \%$, a decrement in the modulus was observed. As shown in Figure 4, the current high number of agglomerates may cause a lubricating effect on the composite. When a tension load was applied to the composite, the shear stress caused sliding in agglomerated rGP particles, resulting in a lubricating effect on the composite.

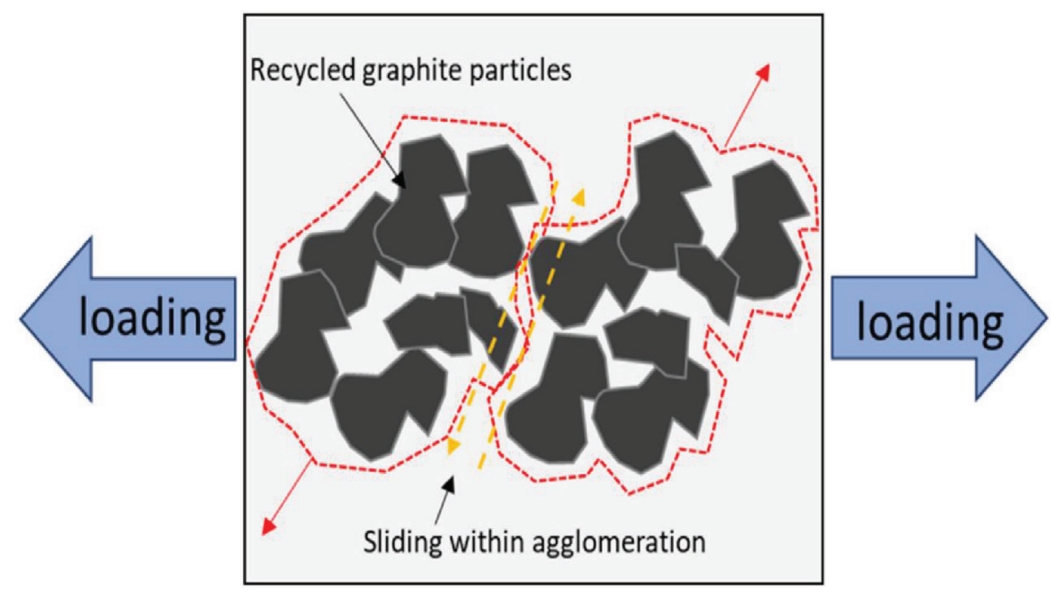

Figure 4: Proposed mechanism of lubricating effect due to filler agglomeration.

\subsection{Morphological Properties}

For the micrograph, the region highlighted with yellow colour square was captured at a magnification of $5000 \times$. Figure 5 shows the SEM micrographs of the fracture specimen of neat PP. From Figure 5(a), the neat PP exhibited a uniform matrix tearing surface. In addition, the microfibrils on the fracture surface of neat PP were clearly observed at higher magnification, as shown in Figure 5(b). The presence of microfibrils was due to the ductile fracture of material after crazing. This finding indicated that the neat PP was a ductile material. The SEM micrographs of fracture surface of $\mathrm{PP} / \mathrm{rGP}$ composites at selected filler contents are displayed in Figures 6 to 8. It can be observed that the rGP was in particulate form and irregular in shape, and the composites exhibited a brittle fracture surface with the addition of rGP. This was due to the addition of more rGP filler, which made the composite more rigid. The SEM result clearly showed that the rGP was highly agglomerated when the filler content was increased. As the filler content increased, the conductive network within PP matrix formed. The proposed mechanism of 
formation of conductive network is displayed in Figure 9. From Figure 6, there was no agglomeration that could be observed and the rGP particles were separated by the PP matrix. Therefore, the PP/rGP composite with $10 \mathrm{wt} \%$ of filler content was insulative. Figure 8 displays that the rGP was agglomerated and the rGP particles were contacted by each particle. This observation indicated that when the rGP particles agglomerated, they initially formed conductive network within the PP matrix. As the filler content increased to $50 \mathrm{wt} \%$, the agglomeration of filler became more visible. The micrograph in Figure 8(b) clearly shows that the rGP particles are highly agglomerated, indicating that $\mathrm{PP} / \mathrm{rGP}$ with $50 \mathrm{wt} \%$ of rGP is the most conductive. In addition, a matrix tear found in Figure 8(b) indicated a lubricating effect on the $\mathrm{PP} / \mathrm{rGP}$ composite with $50 \mathrm{wt} \%$ filler content. Therefore, this finding supported the reason as to why the tensile module of composite reduced at $50 \mathrm{wt} \%$ of filler contents.

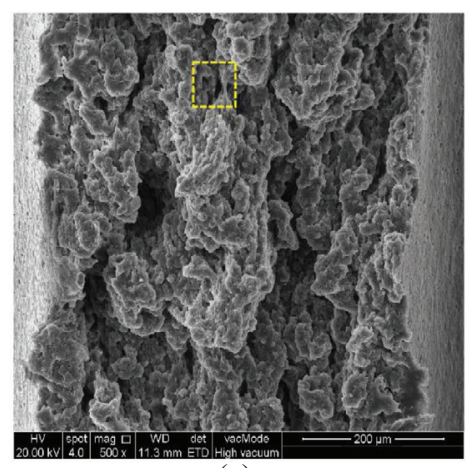

(a)

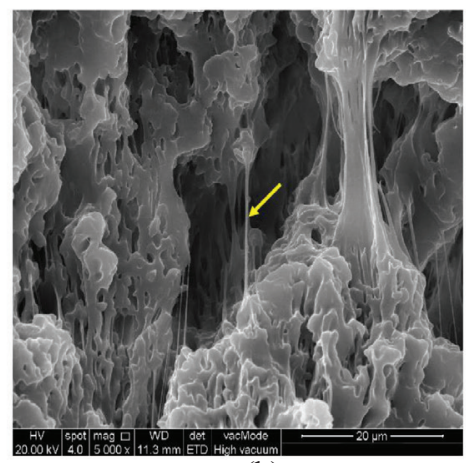

(b)

Figure 5: SEM micrographs of tensile fracture surface for neat PP at (a) 500× and (b) $5000 \times$ magnification.

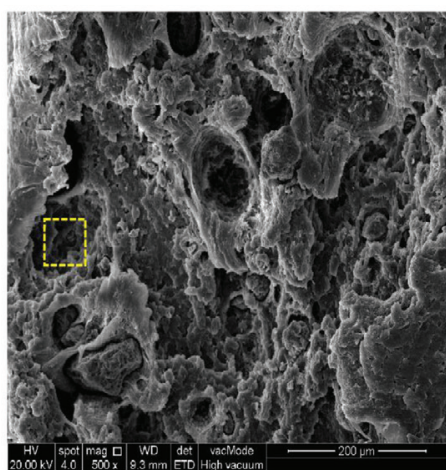

(a)

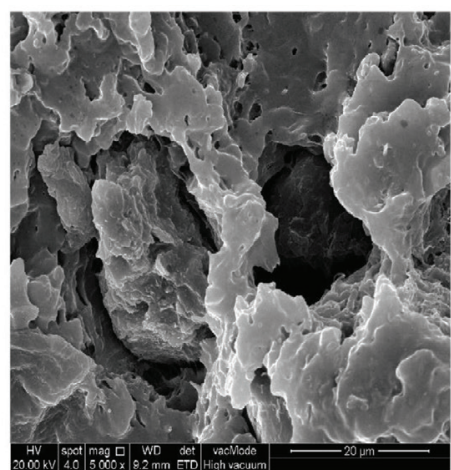

(b)

Figure 6: SEM micrographs of tensile fracture surface of PP/rGP composite with $10 \mathrm{wt} \%$ of filler content at (a) $500 \times$ and (b) $5000 \times$ magnification. 


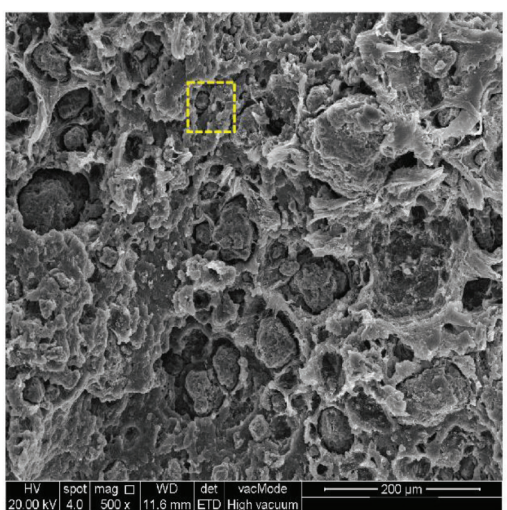

(a)

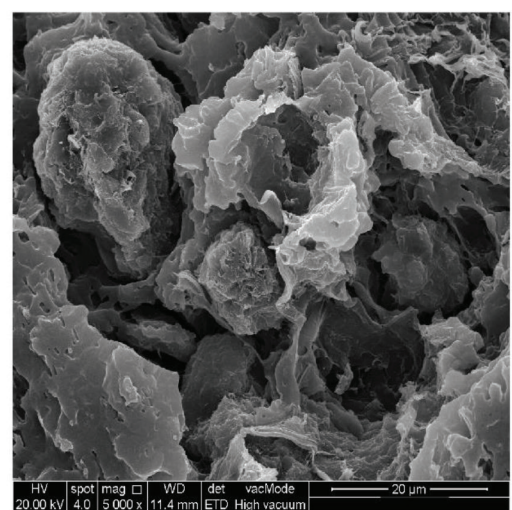

(b)

Figure 7: SEM micrographs of tensile fracture surface of PP/rGP composite with $30 \mathrm{wt} \%$ of filler content at (a) $500 \times$ and (b) $5000 \times$ magnification.

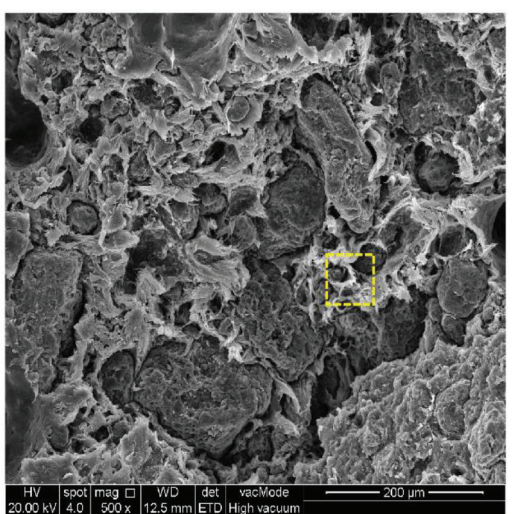

(a)

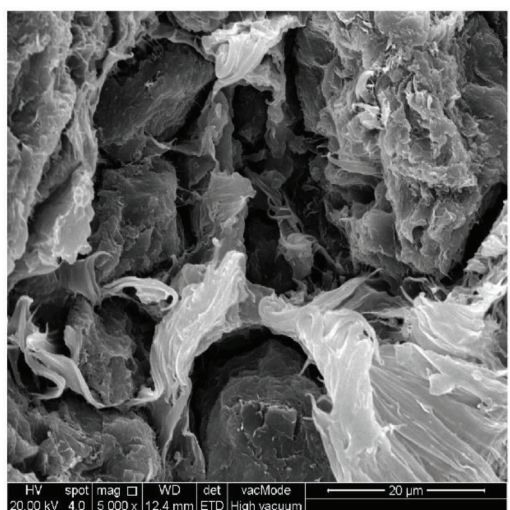

(b)

Figure 8: SEM micrographs of tensile fracture surface of PP/rGP composite with $50 \mathrm{wt} \%$ of filler content at (a) 500× and (b) 5000× magnification. 


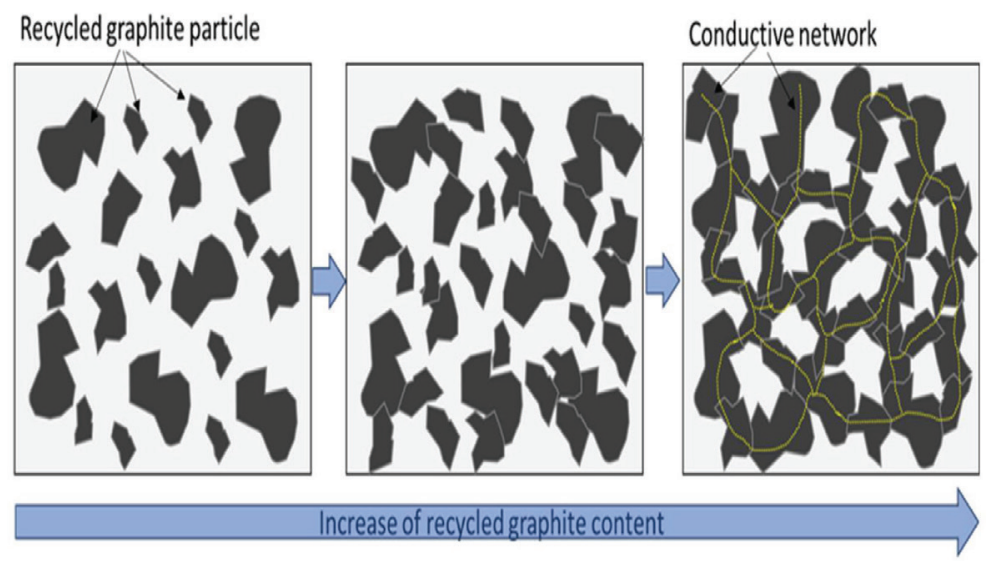

Figure 9: Proposed mechanism for formation of conductive network occur within PP/rGP composite.

\subsection{Thermal Properties}

TGA curves of rGP, neat PP, and PP/rGP with different filler contents are displayed in Figure 10. The results showed that the neat PP remained thermally stable until $340^{\circ} \mathrm{C}$, but it thermally degraded at a faster rate above this temperature. Meanwhile, the raw rGP exhibited only a $2 \%$ weight loss after being heated at a temperature of above $700^{\circ} \mathrm{C}$, which indicated that the rGP has very good natural thermal stability. Table 2 shows the degradation temperature at $10 \%$ of weight loss $\left(T_{d 10 \%}\right)$ for neat PP and composites. When the amount of rGP was increased, $T_{d 10 \%}$ of composites significantly shifted to higher temperatures. This means that the addition of rGP significantly improved the composites' thermal stability. This was observed because the presence of rGP provided a thermal shielding effect on PP matrix. As shown in Figure 11, the PP chains exploded and thermally degraded from direct heat. The presence of rGP particles, on the other hand, prevented a portion of the PP chain from exploding due to direct heat, resulting in a thermal shielding effect. Therefore, the thermal degradation process of PP matrix was delayed due to the thermal shielding effect, and the degradation temperature of composites shifted to higher temperature. The addition of graphite generally improved the thermal stability of composites and this finding was similar to studies by other researchers. ${ }^{13,14}$ 


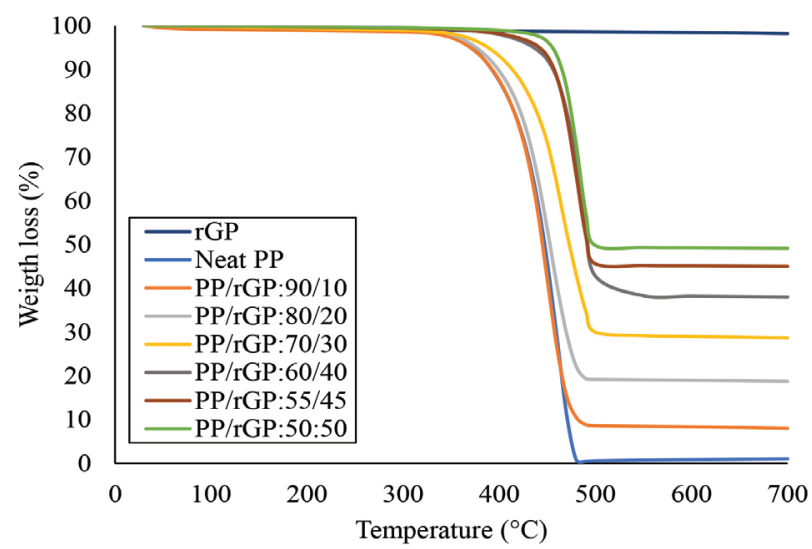

Figure 10: TGA curves of PP/rGP composites with different filler contents, neat PP and raw recycled graphite.

Table 2: $T_{d 10 \%}$ of PP/rGP composites with various filler contents.

\begin{tabular}{lcc}
\hline Sample & $\mathbf{T}_{\mathbf{d} 10 \%}\left({ }^{\circ} \mathbf{C}\right)$ & Residue (\%) \\
\hline Neat PP & 392 & 1.1 \\
PP/rGP:90/10 & 395 & 8.0 \\
PP/rGP:80/20 & 403 & 18.8 \\
PP/rGP:70/30 & 414 & 28.7 \\
PP/rGP:60/40 & 456 & 38.1 \\
PP/rGP:55/45 & 459 & 45.1 \\
PP/rGP:50/50 & 465 & 49.2 \\
\hline
\end{tabular}

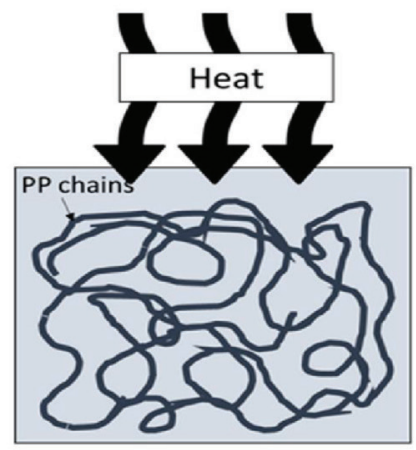

(a)

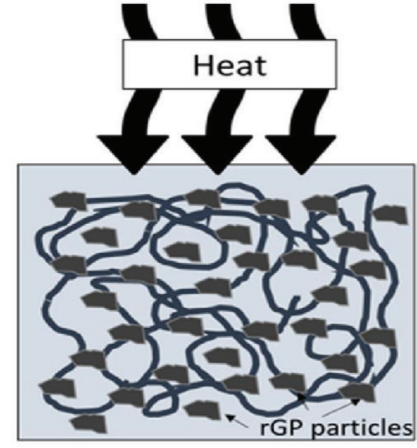

(b)

Figure 11: Different idealised thermal effects on specimen (a) without rGP and (b) with thermal shielding effect from rGP. 


\section{CONCLUSION}

In conclusion, the EDM electrode scrap obtained from the machining industry was able to be recycled as a conductive filler for the production of conductive composite. In terms of compounding behaviour, the processing torque of $\mathrm{PP} / \mathrm{rGP}$ compounding increased with $\mathrm{rGP}$ content. The PP/rGP composite exhibited a percolation content at $30 \mathrm{wt} \%$ of filler content, and the insulative composite initially changed to antistatic material. Moreover, the PP/rGP composite filled with $50 \mathrm{wt} \%$ of rGP achieved a surface resistivity of $10^{5} \mathrm{ohm} / \mathrm{sq}$, which shows that the composite can be used as static dissipative material. On the other hand, the tensile strength of PP/rGP composites decreased by approximately $60 \%$ as the filler content increased to $50 \mathrm{wt} \%$. The tensile modulus of this composite increased and showed an optimum tensile modulus at a filler content of $45 \mathrm{wt} \%$. The tensile modulus of composite decreased as the filler content was increased above $45 \mathrm{wt} \%$ due to the plasticising effect of rGP. The thermal stability of composite greatly increased with the addition of rGP. The morphological analysis confirmed that the increased rGP content was able to form a conductive network within the PP matrix in the composite. Therefore, this study found that rGP made from EDM electrode scrap has the potential to be used as a conductive filler for producing conductive composite material.

\section{ACKNOWLEDGEMENT}

The authors would like to thank Pre-Tech Solution Sdn Bhd for giving the EDM wastes.

\section{REFERENCES}

1. Zhang, W., Dehghani-Sanij, A. A. \& Blackburn, R. S. (2007). Carbon based conductive polymer composites. J. Mater. Sci., 42(10), 3408-3418. https://doi. org/10.1007/s10853-007-1688-5

2. Hidayah, I. N. \& Mariatti, M. (2012). Properties of single and hydrid aluminum and silver filled high-density polyethylene composites. J. Thermoplast. Compos. Mater., 25(2), 209-221. https://doi.org/10.1177/0892705711406161

3. Thongruang, W., Spontak, R. J. \& Balik, C. M. (2002). Correlated electrical conductivity and mechanical property analysis of high-density polyethylene filled with graphite and carbon fibre. Polym., 43(8), 2279-2286. https://doi.org/10.1016/ S0032-3861(02)00043-5

4. Bouknaitir, I. et al. (2017). Electrical properties of conducting polymer composites: Experimental and modeling approaches. Spectrosc. Lett., 50(4), 196-199. https:// doi.org/10.1080/00387010.2017.1282522 
5. Klocke, F. et al. (2013). Analysis of material removal rate and electrode wear in sinking EDM roughing strategies using different graphite grades. Proc. CIRP., 6, 163-167. https://doi.org/10.1016/j.procir.2013.03.079

6. Chun, K. S., Husseinsyah, S. \& Osman, H. (2015). Utilization of cocoa pod husk as filler in polypropylene biocomposites: Effect of maleated polypropylene. J. Thermoplast. Compos. Mater., 28(11), 1507-1521. https://doi. org/10.1177\%2F0892705713513291

7. Chun, K. S., Husseinsyah, S. \& Yeng, C. M. (2016). Green composites from kapok husk and recycled polypropylene: Processing torque, tensile, and thermal, and morphological properties. J. Thermoplast. Compos. Mater., 29(11), 1517-1535. https://doi.org/10.1177\%2F0892705715569822

8. Chun, K. S., Husseinsyah, S. \& Yeng, C. M. (2017). Torque rheological properties of polypropylene/cocoa pod husk composites. J. Thermoplast. Compos. Mater., 30(9), 1217-1227. https://doi.org/10.1177\%2F0892705715618743

9. Gulrez, S. K. H. et al. (2014). A review on electrically conductive polypropylene and polyethylene. Polym. Compos., 35(5), 900-914. https://doi.org/10.1002/ pc. 22734

10. Li, J. \& Kim., J. K. (2007). Percolation threshold of conducting polymer composites containing 3D randomly distributed graphite nanoplatelets. Compos. Sci. Technol., 67(10), 2114-2120. https://doi.org/10.1016/j.compscitech.2006.11.010

11. Parvin, N. et al. (2013). Structures and mechanical properties of talc and carbon black reinforced high density polyethylene composites: Effects of organic and inorganic fillers. J. Bangladesh Acad. Sci., 37(1), 11-20. https://doi.org/10.3329/ jbas.v37i1.15675

12. Bhagat, S. \& Verma, P. K. (2007). Effect of graphite filler on mechanical behaviour of epoxy composite. Int. J. Emer. Technol. Adv. Eng., 3(2), 427-430.

13. Galikhanov, M. F., Deberdeev, R. Y. \& Mochalova, E. N. (2017). Investigating the electret properties of polystyrene and graphite composites. Int. Polym. Sci. Technol., 44(1), 49-52. https://doi.org/10.1177\%2F0307174X1704400110

14. Pandey, A. K., Singh, K. \& Kar, K. K. (2017). Thermo-mechanical properties of graphite-reinforced high-density polyethylene composites and its structureproperty corelationship. J. Compos. Mater., 51(12), 1769-1782. https://doi. org/10.1177\%2F0021998316683782 